07

\title{
Формирование и изучение оптических свойств светодиодов на основе микропирамид GaN c полупрозрачным контактом Ni/Au/графен
}

\author{
(C) A.В. Бабичев ${ }^{1}$, Д.В. Денисов ${ }^{2,3}$, M. Tchernycheva ${ }^{4}$, F.H. Julien ${ }^{4}$, \\ H. Zhang ${ }^{4,5}$
}

${ }^{1}$ Санкт-Петербургский национальный исследовательский университет информационных технологий, механики и оптики, Санкт-Петербург, Россия

${ }^{2}$ Санкт-Петербургский государственный электротехнический университет „ЛЭТИ“, Санкт-Петербург, Россия

${ }^{3}$ Санкт-Петербургский национальный исследовательский академический университет РАН, Санкт-Петербург, Россия

${ }^{4}$ Centre for Nanoscience and Nanotechnology (C2N Orsay), CNRS UMR9001, Université Paris Sud, Université Paris Saclay, Orsay, France

${ }^{5}$ École Polytechnique Fédérale de Lausanne, Lausanne, Switzerland

E-mail: a.babichev@mail.ioffe.ru

Поступило в Редакцию 10 мая 2018 г.

Представлены результаты исследований технологических режимов формирования светодиодов на основе микропирамид $\mathrm{InGaN} / \mathrm{GaN}$ в геометрии ядро-оболочка, использующих полупрозрачный контакт $\mathrm{Ni} / \mathrm{Au} /$ графен. Структуры сформированы методом металлоорганической газофазной эпитаксии. Отработка режимов нанесения графена большой площади, полученного методом химического осаждения из газовой фазы, позволила использовать его в качестве контакта для токовой инжекции. Сформированные светодиоды демонстрируют электролюминесценцию на длине волны излучения $520-540 \mathrm{~nm}$. Данные источники излучения представляют интерес для биомедицинских приложений, в частности для оптогенетики.

DOI: 10.21883/PJTF.2018.23.47021.17378

Гибкие светодиодные гетероструктуры InGaN/GaN на основе нитевидных кристаллов (НК), микропирамид представляют интерес для ряда практических приложений, в том числе для биомедицины (оптогене- 
тики) [1]. Более того, наноструктуры в геометрии НК [2] или микропирамид [3] позволяют получить более низкую плотность дислокаций, чем в случае планарных гетероструктур на основе $\mathrm{GaN}$, и уменьшают встроенное электрическое поле за счет возможности выращивания квантовых ям на неполярных или полуполярных плоскостях [4]. Кроме того, данные наноструктуры могут быть использованы для создания механически гибких оптоэлектронных устройств, однако для этого необходимы прозрачные гибкие контакты с низким контактным сопротивлением [5]. Широко используемый в промышленности оксид индия-олова (ITO) неприменим в качестве гибкого контакта. В качестве альтернативы ITO при создании гибких контактов в литературе были предложены: графен [6], углеродные нанотрубки [7], серебряные нитевидные кристаллы (СНК) [8] и гибридные контакты на основе графена и СНК [9]. Из представленного ряда материалов графен, полученный методом химического осаждения из газовой фазы (CVD), может быть произведен в промышленных масштабах с контролируемым числом слоев, прозрачностью и проводимостью [10]. Ранее были проведены исследования по характеризации проводимости, рамановских спектров, исследования поверхности графена методом туннельной микроскопии при расположении графена на поверхности микропирамид [11]. Достигнутое контактное сопротивление $0.8 \pm 0.2 \mathrm{k} \Omega \cdot \mu \mathrm{m}$ сопоставимо с результатами, полученными на планарных структурах, что свидетельствует о перспективности применения графена в качестве прозрачного контакта к светодиодам на основе микропирамид $\mathrm{GaN}$. В настоящей работе представлены данные по отработке условий нанесения CVDграфена на массив светодиодных микропирамид, а также результаты исследования их оптических свойств в качестве основы для последующего создания гибких светодиодов $\mathrm{InGaN} / \mathrm{GaN}$ с графеновым прозрачным контактом.

Микропирамиды InGaN/GaN выращены селективно на поверхности сапфира с планарным слоем $n$-GaN через окна в диэлектрической маске $[12,13]$. В качестве методики роста использована металлоорганическая газофазная эпитаксия. Светодиодные пирамиды сформированы в радиальной геометрии ядро-оболочка и включают область ядра $(n-\mathrm{GaN})$, селективно выращенного через окна в маске $\mathrm{SiN}$, набор квантовых ям (InGaN) и оболочку на основе $p$-GaN. Период расположения микропирамид на подложке составляет $1 \mu \mathrm{m}$, высота пирамид $-1.1 \mu \mathrm{m}$. В ходе эксперимента использовался графен, содержащий несколько слоев (в среднем, четыре монослоя $[11,14,15])$, полученный

Письма в ЖТФ, 2018, том 44, вып. 23 
методом CVD на поверхности $\mathrm{Si} / \mathrm{SiO}_{2} / \mathrm{Ni}$. Число слоев определялось на основе данных атомно-силовой микроскопии, а также рамановской спектроскопии [11]. Состоящий из нескольких слоев графен демонстрирует меньшее плоскостное сопротивление, типичные значения которого составляют 180-350 $\Omega$ на квадрат [11,16], а также бо́льшую механическую стабильность в сравнении с монослойным графеном, что и предопределило его выбор при формировании светодиодных структур на основе микропирамид.

Формирование светодиода начинается с вытравливания области $n$-контакта методом индуктивно-связанной плазмы до планарного слоя $n$-GaN. Металлизация n-контакта формируется за счет последовательного напыления $\mathrm{Ti} / \mathrm{Al} / \mathrm{Ti} / \mathrm{Au}$ с толщинами 10/40/30/250 nm соответственно; $p$-контактная площадка сформирована напылением $\mathrm{Ni}(10 \mathrm{~nm}) / \mathrm{Au}(250 \mathrm{~nm})$ в углу мезы для ультразвуковой разварки контактов и обходит рамкой по контуру мезу для улучшения равномерности токовой инжекции. Дополнительно к контактной площадке на всю поверхность мезы был нанесен полупрозрачный контактный слой $\mathrm{Ni}(5 \mathrm{~nm}) / \mathrm{Au}(5 \mathrm{~nm})$. Данный слой использован для понижения контактного сопротивления к графену и улучшения растекания тока по граням микропирамид, которых графен касается преимущественно в области вершин. Токовая накачка осуществляется через слой графена, нанесенного на последнем шаге процессирования.

Ранее показана возможность использования слоя $\mathrm{Ni}(4 \mathrm{~nm}) / \mathrm{Au}(4 \mathrm{~nm})$ в качестве полупрозрачного непрерывного контакта большой площади, обеспечивающего эффективную электролюминесценцию (ЭЛ) светодиодов на основе планарных слоев InGaN/GaN [17]. В ходе отдельных экспериментов были сформированы тестовые светодиодные гетероструктуры на основе массива микропирамид с покрывающим слоем $\mathrm{Ni}(5 \mathrm{~nm}) / \mathrm{Au}(5 \mathrm{~nm})$ без нанесения графена. Показано, что использование данного слоя не обеспечивает латерального протекания тока и ЭЛ светодиода. Требуется нанесение графена для токовой инжекции.

Перед переносом графена на поверхность мезы, покрытой полупрозрачным слоем $\mathrm{Ni} / \mathrm{Au}$, производится его отделение от подложки $\left(\mathrm{Si} / \mathrm{SiO}_{2} / \mathrm{Ni}\right)$ за счет жидкостного травления слоя никеля в растворе хлорида железа $\left(\mathrm{FeCl}_{3}\right)$. Дополнительный шаг травления $\mathrm{SiO}_{2}$ в растворе разбавленной плавиковой кислоты не используется для исключения деградации и изменения уровня легирования образцов [16]. После отделения от подложки графен переносится в раствор деионизованной

Письма в ЖТФ, 2018, том 44, вып. 23 

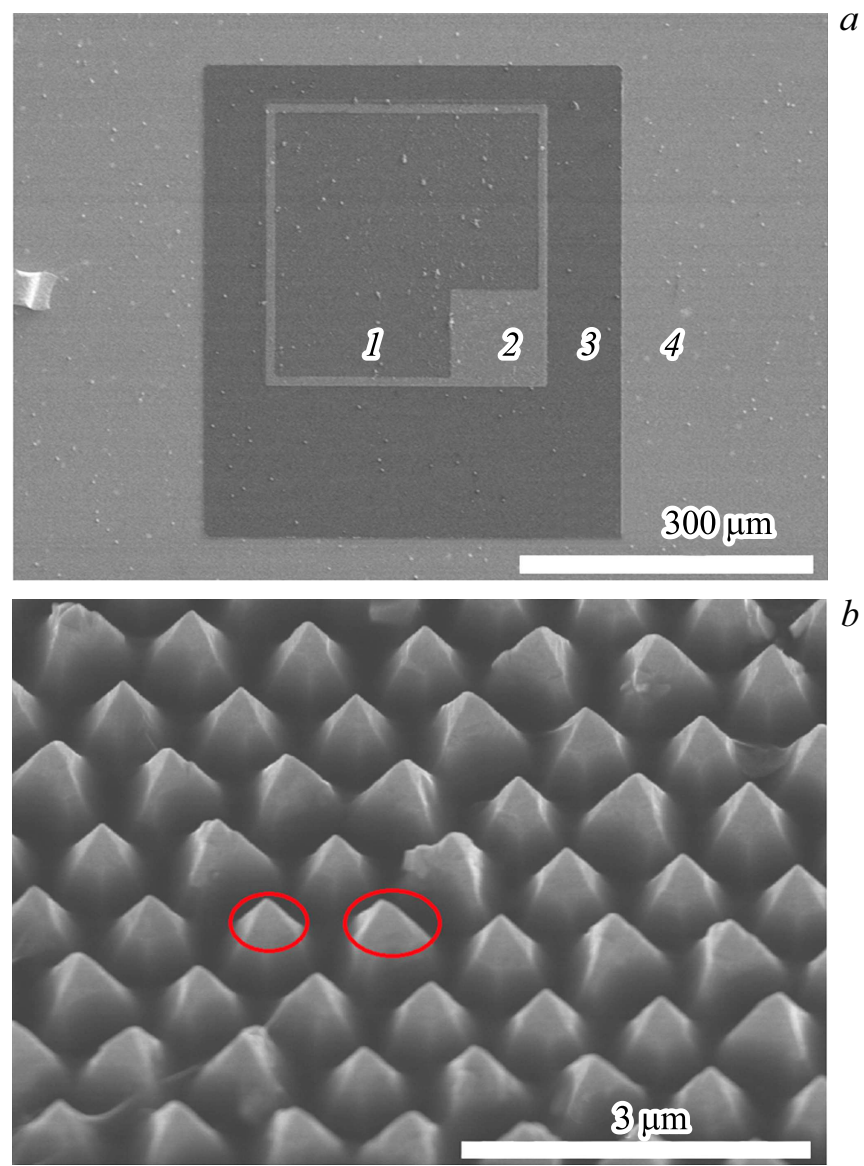

Рис. 1. Изображения, полученные методом СЭМ. $a-$ меза светодиода. 1 - область мезы, покрытая графеном; 2 - p-металлизация; 3 - область вытравленной мезы до слоя $n$ - $\mathrm{GaN} ; 4$ - область $n$-металлизации. $b-$ увеличенная область 1. Кружками обведена область прилегания графена к вершине микропирамиды. $c$ - изображения, полученные методом СТМ, демонстрирующие профиль провисания графена (верхний фрагмент) и карту (из работы [19]), на которой линией отмечен путь сканирования СТМ-иглы (нижний фрагмент).

Письма в ЖТФ, 2018, том 44, вып. 23 

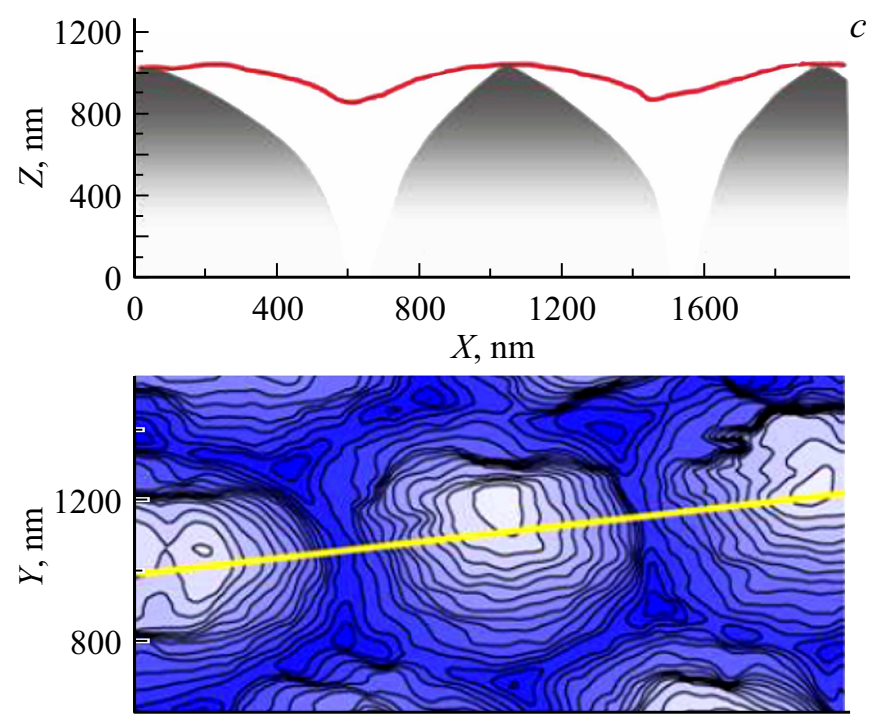

Рис. 1 (продолжение).

воды (сопротивление $18 \mathrm{M} \Omega \cdot \mathrm{cm}$ ) с помощью подложки-,носителя“ с целью промывки от остатков $\mathrm{FeCl}_{3}$. Подложка сапфира со сформированными мезами светодиодов погружается в раствор деионизованной воды, в котором располагается графен после отмывки. Отработка условий переноса позволяет добиться равномерного расположения графена (без разрывов) на поверхности массива микропирамид (рис. 1,b). Вытравливание графена вне области мез производится в кислородсодержащей плазме после проведения этапа оптической литографии. Для повышения проводимости графена проводилось легирование образцов за счет расположения в парах соляной кислоты (аналогично подходу, описанному в [18]). Типичное изображение сканирующей электронной микроскопии (СЭМ) сформированных мез светодиодов с полупрозрачным контактом $\mathrm{Ni} / \mathrm{Au} / г$ рафен представлено на рис. 1, a. Размер мезы составляет $300 \times 300 \mu \mathrm{m}$. На рис. $1, b$ приведено СЭМ-изображение микропирамид с бо́льшим увеличением. Графен осуществляет контакт преимущественно с вершинами микропирамид (типичные области прилегания микропирамид отмечены кружками). Дополнительные исследо-

Письма в ЖТФ, 2018, том 44, вып. 23 
вания образцов методом сканирующей туннельной микроскопии (СТМ) позволили оценить провисание графена, которое составляет порядка $200-300 \mathrm{~nm}$ от вершины микропирамид $[11,19]$. Профиль провисания графена, представленный авторами в работе [19], показан также на рис. $1, c$. Несмотря на малую площадь контакта, благодаря присутствию на поверхности $p$-GaN слоя $\mathrm{Ni} / \mathrm{Au}$ графен обеспечивает достаточную инжекцию носителей заряда и их распределение по поверхности микропирамид. Предельная плотность тока, измеренная для четырехслойного графена, составляет $10^{8}-10^{9} \mathrm{~A} / \mathrm{cm}^{2}$ [16]. Данное значение показывает, что графен не ограничивает инжекцию носителей при токовой накачке.

Вольт-амперные характеристики (ВАХ) измерялись с использованием источника-измерителя тока Keithley 2636 и зондовой станции Janis. Типичная BAX светодиодной гетероструктуры с контактом $\mathrm{Ni} / \mathrm{Au} /$ графен представлена на рис. $2, a$. С увеличением токовой накачки наблюдается ЭЛ (соответствует напряжению более $4 \mathrm{~V}$ ). Кривая демонстрирует отклонение от идеальной диодной характеристики за счет вкладов шунтирующего и последовательного сопротивлений. Вставка на рис. 2, $a$ демонстрирует визуализацию ЭЛ, соответствующую току накачки в $25 \mathrm{~mA}$ (плотности тока $28 \mathrm{~A} / \mathrm{cm}^{2}$ ). Наблюдается равномерная прокачка всей области мезы через графеновый контакт на макромасштабе (интенсивность свечения микропирамид в середине мезы сопоставима с интенсивностью свечения вблизи края мезы), что свидетельствует о протекании тока по поверхности графена на масштабе в сотни микрометров. Также отметим локальные неоднородности свечения, связанные с наличием дефектов в массиве микропирамид.

Спектры ЭЛ при различных токах накачки измерялись при комнатной температуре с помощью спектрометра Jobin Yvon c фокальным расстоянием $460 \mathrm{~mm}$ с CCD-камерой (спектральное разрешение в исследуемом диапазоне составило $\sim 1 \mathrm{~nm}$ ) и представлены на рис. $2, b$. Максимальная эффективность преобразования соответствует плотности тока $1.3 \mathrm{~A} / \mathrm{cm}^{2}$ (рис. 3). С увеличением плотности тока наблюдается последовательный рост интенсивности ЭЛ (рис. 2,3), а также слабый сдвиг максимума интенсивности спектра ЭЛ в коротковолновую область спектра излучения (с 537 до $518 \mathrm{~nm}$ ). Оцененная ширина на полувысоте (FWHM) спектров излучения находится в диапазоне $265-303 \mathrm{meV}$. Типичные значения FWHM, наблюдаемые экспериментально, составляют (5-8) $k T$ (см. данные по планарным $\mathrm{HK} \mathrm{InGaN} / \mathrm{GaN}$ [20] и одиночным $\mathrm{HK}$ InGaN/GaN [4]), что превышает тепловое уширение

Письма в ЖТФ, 2018, том 44, вып. 23 


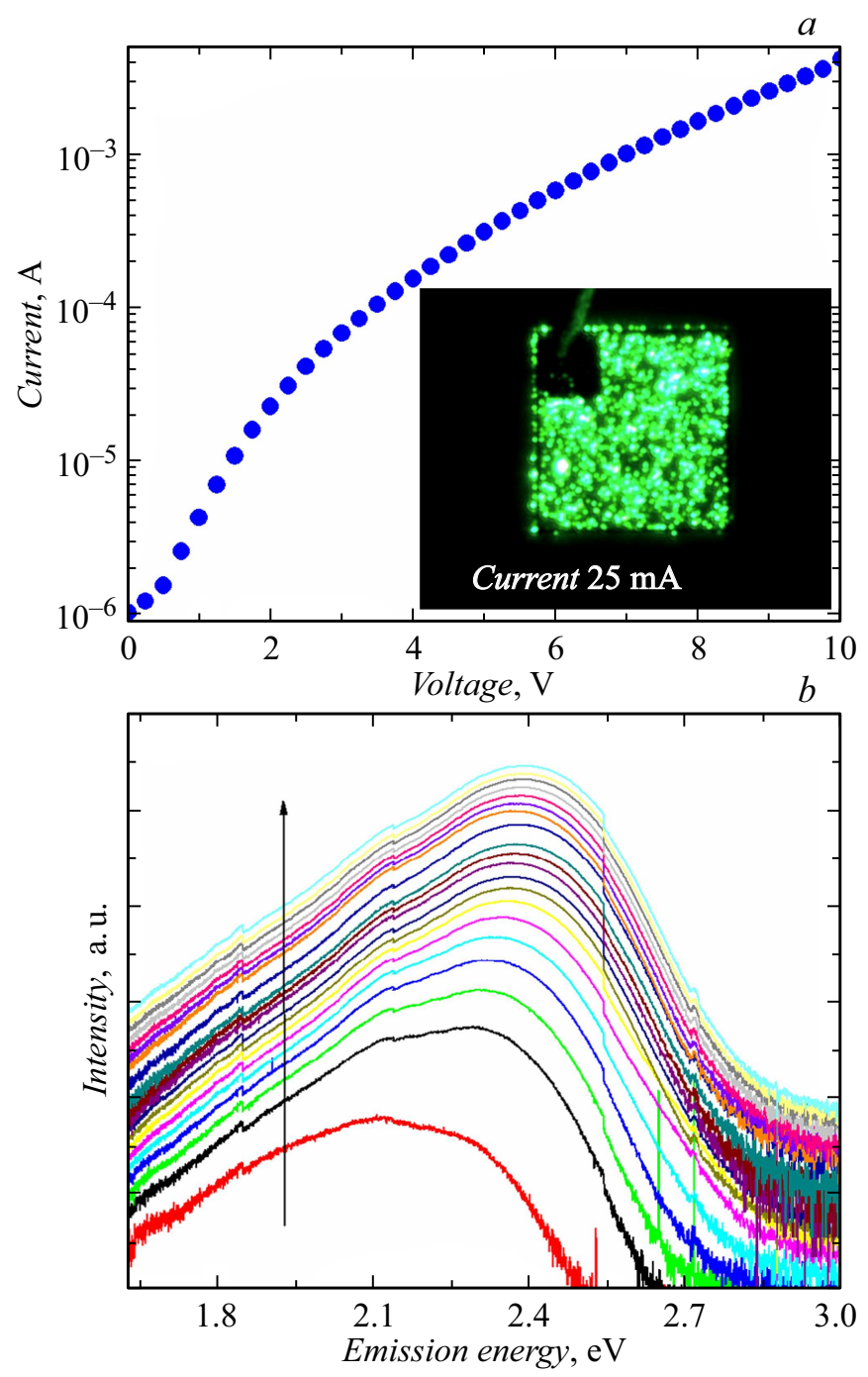

Рис. 2. $a-$ ВАХ светодиода с полупрозрачным контактом $\mathrm{Ni} / \mathrm{Au} /$ графен большой площади (в полулогарифмическом масштабе). На вставке - изображение ЭЛ гетероструктуры при токе накачки $25 \mathrm{~mA} . b-$ спектры ЭЛ, соответствующие различным токам накачки (в полулогарифмическом масштабе). Стрелка отображает направление увеличения тока от 0.15 до $32 \mathrm{~mA}$.

Письма в ЖТФ, 2018, том 44, вып. 23 


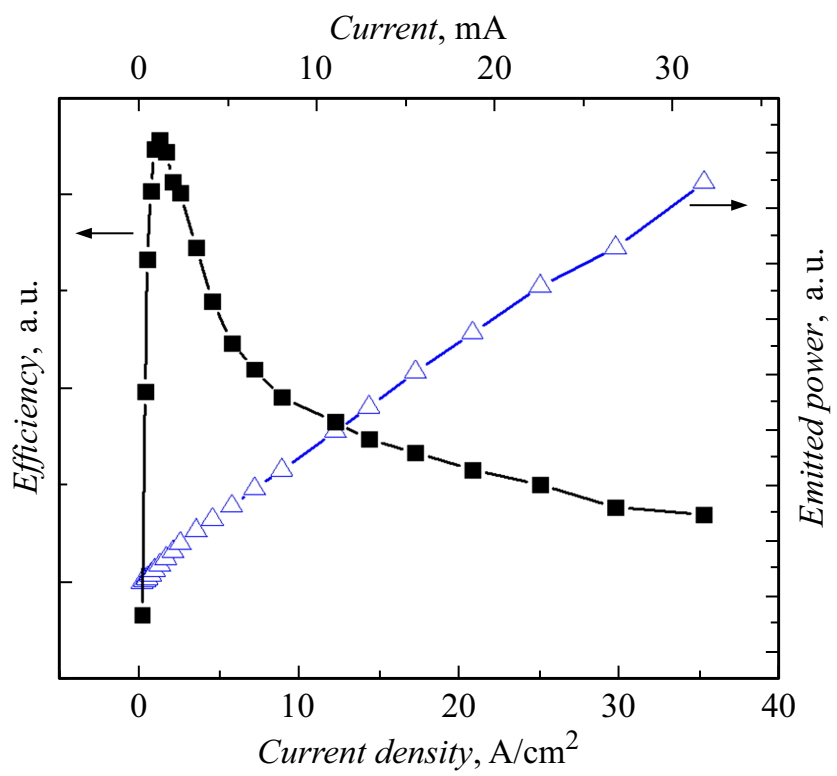

Рис. 3. Зависимости эффективности преобразования и интенсивности излучения от плотности тока накачки.

спектра (расчетная величина гауссова распределения $1.8 k T \approx 47 \mathrm{meV}$ ). Значительное уширение спектра ЭЛ может быть связано с неоднородностью состава квантовых ям InGaN в массиве микропирамид, а также с неоднородностью токовой инжекции.

Таким образом, в ходе выполнения работы проведена отработка режимов формирования графенового контакта к массиву микропирамид, сформированы светодиодные гетероструктуры на основе массива микропирамид $\mathrm{InGaN} / \mathrm{GaN}$ с полупрозрачным контактом $\mathrm{Ni} / \mathrm{Au} /$ графен большой площади. Продемонстрирована диодная ВАХ, светодиодные гетероструктуры демонстрируют ЭЛ на длине волны излучения $520-540 \mathrm{~nm}$.

Авторы благодарят О. Крылюк за предоставление образцов микропирамид, а также С.А. Рыкова и С.Т. Ганбарову за характеризацию образцов методом сканирующей туннельной микроскопии.

Письма в ЖТФ, 2018, том 44, вып. 23 
Работа выполнена при частичной поддержке Гранта Президента Российской Федерации (№ МК-5418.2018.8). Д.В. Денисов также благодарит за частичную поддержку исследований Министерство образования и науки РФ (государственное задание № 16.9789.2017/БЧ).

\section{Список литературы}

[1] Guan N., Dai X., Babichev A.V., Julien F.H., Tchernycheva M. // Chem. Sci. 2017. V. 8. P. 7904-7911.

[2] Koester R., Hwang J.-S., Salomon D., Chen X., Bougerol C., Barnes J.-P., Dang D.L.S., Rigutti L., Bugallo A.L., Jacopin G., Tchernycheva M., Durand C., Eymery J. // Nano Lett. 2011. V. 11. P. 4839-4845.

[3] Bi Z., Gustafsson A., Lenrick F., Lindgren D., Hultin O., Wallenberg L.R., Ohlsson B.J., Monemar B., Samuelson L. // J. Appl. Phys. 2018. V. 123. P. 025102.

[4] Tchernycheva M., Lavenus P., Zhang H., Babichev A.V., Jacopin G., Shahmohammadi M., Julien F.H., Ciechonski R., Vescovi G., Kryliouk O. // Nano Lett. 2014. V. 14. P. 2456-2465.

[5] Dai X., Messanvi A., Zhang H., Durand C., Eymery J., Bougerol C., Julien F.H., Tchernycheva M. // Nano Lett. 2015. V. 15. P. 6958-6964.

[6] Kim K.S., Zhao Y., Jang H., Lee S.Y., Kim J.M., Kim K.S., Ahn J.-H., Kim P., Choi J.-Y., Hong B.H. // Nature. 2009. V. 457. P. 706-710.

[7] Wang C., Chien J.-C., Takei K., Takahashi T., Nah J., Niknejad A.M., Javey A. // Nano Lett. 2012. V. 12. P. 1527-1533.

[8] Hu L., Kim H.S., Lee J.-Y., Peumans P., Cui Y. // ACS Nano. 2010. V. 4. P. 2955-2963.

[9] Lee M.-S., Lee K., Kim S.-Y., Lee H., Park J., Choi K.-H., Kim H.-K., Kim D.-G., Lee D.-Y., Nam S.W., Park J.-U. // Nano Lett. 2013. V. 13. P. 2814-2821.

[10] Xu X., Zhang Z., Dong J., Yi D., Niu J., Wu M., Lin L., Yin R., Li M., Zhou J., Wang S., Su J., Duan X., Gao P., Jiang Y., Wu X., Peng H., Ruoff R.S., Liu Z., Yu D., Wang E., Ding F., Liu K. // Sci. Bull. 2017. V. 62. P. 1074-1080.

[11] Babichev A.V., Rykov S.A., Tchernycheva M., Smirnov A.N., Davydov V.Yu., Kumzerov Y.A., Butko V.Y. // ACS Appl. Mater. Interfaces. 2015. V. 8. P. 240246.

[12] Stankevič T., Mickevičius S., Schou Nielsen M., Kryliouk O., Ciechonski R., Vescovi G., Bi Z., Mikkelsen A., Samuelson L., Gundlach C., Feidenhans'l R. // J. Appl. Cryst. 2015. V. 48. P. 344-349.

[13] Дубровский В.Г. // Письма в ЖТФ. 2015. Т. 41. В. 23. С. 49-53.

[14] Babichev A.V., Gasumyants V.E., Butko V.Y. // J. Appl. Phys. 2013. V. 113. P. 076101. 
[15] Babichev A.V., Zhang H., Lavenus P., Julien F.H., Egorov A.Y., Lin Y.T., Tu L.W., Tchernycheva M. // Appl. Phys. Lett. 2013. V. 103. P. 201103.

[16] Babichev A.V., Gasumyants V.E., Egorov A.Y., Vitusevich S., Tchernycheva M. // Nanotechnology. 2014. V. 25. P. 335707.

[17] Chuang R.W., Zou A.Q., Lee H.P., Dong Z.J., Xiong F.F., Shih R., Bremser M., Juergensen H. // MRS Online Proc. Libr. 1998. V. 537. P. g6.42.

[18] Bae S., Kim H., Lee Y., Xu X., Park J.S., Zheng Y., Balakrishnan J., Lei T., Kim H.R., Song Y.I., Kim Y.-J., Kim K.S., Özyilmaz B., Ahn J.-H., Hong B.H., Iijima S. // Nature Nanotechnol. 2010. V. 5. P. 574-578.

[19] Ganbarova S.T., Babichev A.V., Rykov S.A. // J. Phys.: Conf. Ser. 2017. V. 816. P. 012032.

[20] Chhajed S., Xi Y., Li Y.-L., Gessmann Th., Schubert E.F. // J. Appl. Phys. 2005. V. 97. P. 054506. 